Для реализации своего замысла Р. Карнап провел много работы по развитию специального логического языка и правил индуктивного вывода. Однако ему удалось создать приемлемую индуктивную логику подтверждения только для очень простых языков, что не позволяло применить ее к реальной научной практике. При дальнейшем развитии проект Р. Карнапа столкнулся с массой технических трудностей [4].

$\mathrm{C}$ нашей точки зрения, проблема подтверждения связана в большей мере прагматическими соображениями. Однако следует отметить, что прагматика научного познания остается пока слабо разработанной проблемой. Прагматика науки сопряжена с отсеиванием лишних гипотез, эвристическими факторами ускоренного перебора вариантов, финитизации этого процесса и т.п. (примером могут служить работы Г. Гигеренцера) [5], [6], [7].

Прагматические соображения связаны с тем, что выбираются лучшие варианты из того, что есть; используются различные процедуры сравнительных оценок, применение неформальных норм, выделяются наиболее убедительные (на данный момент, в данных обстоятельствах) свидетельства.

С прагматической точки зрения, гипотеза рассматривается как условно (a не окончательно) подтвержденная. Это соответствует установкам прагматизма (Дж. Дьюи, Ч. Пирсон, К.-О. Аппель и др) [8]. В известном смысле, подтверждение гипотезы происходит как некий «удовлетворяющий» (не оптимальный) выбор - что заставляет вспомнить о концепции Г. А. Саймона (ограниченная рациональность) [9], [10].

$$
* * *
$$

1. Гемпель К.Г. Логика объяснения. - М.: Дом интеллектуальной книги, Русское феноменологическое общество, 1998.

2. Hempel C. G. Studies in the Logic of Confirmation. Mind, 54 (213). P. 97-121.

3. $\quad$ Гудмен Н. Способы создания миров. - М.: Идея-Пресс, Праксис, 2001.

4. The problem of Inductive Logic / Lakatos I. (ed). Amsterdam, North-Holland, 1968.

5. Gigerenzer G. Messung und Modellbildung in der Psychologie. UTB/Reinhardt, Munchen/Basel, 1981.

6. Gigerenzer G. Adaptive Thinking. Rationality in Real Word. Oxford, Oxford University Press, 2000.

7. Gigerenzer G. Risk Sawy: How to Make Good Decisions. London, Penguin Books, 2015.

8. Ralston Sh. Philosophical Pragmatism and International Relations. Essays for a Bold New World. New York: Lexington, 2013.

9. Саймон Г.А., Марш Д. Административное поведение. - М.: Мир, 1974.

\title{
Ушаков Е.В.
}

Моральные проблемы нейронаук: основные дискуссионные поля нейроэтики

Российская академия народного хозяйства и государственной службы при Президенте Российской Федераџии (Северо-Западный институт управления РАНХиГС) (Россия, Санкт-Петербург)

doi: 10.18411/trnio-10-2021-155

\section{Аннотация}

В статье рассматривается тематика нейронаук с точки зрения возникающих моральных проблем. Затрагиваются некоторые направления нейронауки, которые сегодня обсуждаются общественностью. Моральные проблемы нейронауки стали предметом новых исследований и дискуссий. Нейроэтика - новое формирующееся русло дебатов. В статье делается вывод о том, что нейроэтические проблемы пока совершенно мало изучены, однако связанные с ними риски заставляют активизироваться уже сейчас.

Ключевые слова: этика, философия сознания, когнитивные науки, нейронауки, нейроэтика, моральные проблемы науки, энхансмент. 


\section{Abstract}

The article examines the subject of neurosciences from the point of view of emerging moral problems. Some areas of neuroscience that are currently being discussed by the public are considered. The moral issues of neuroscience have become the subject of new research and debate. Neuroethics is an emerging new mainstream of debate. The article concludes that neuroethical problems have so far been studied very little, but the risks associated with them are forcing us to intensify even now.

Keywords: ethics, philosophy of mind, cognitive sciences, neurosciences, neuroethics, moral issues of science, enhancement.

В современном мире огромное значение приобрела группа нейронаук (или когнитивных наук), исследующих и моделирующих работу сознания [1].

В эту довольно обширную рубрику подпадает немалое число (во многом пересекающихся) направлений, таких как: философия сознания, логика, искусственный интеллект, нейронные сети, машинное обучение, нейролингвистика, нейроэкономика, нейрофармакология и другие.

Развитие этого комплекса наук создает немало моральных проблем: многие из них пока находятся в недостаточной степени разработки. В этой связи сегодня активно формируется такое новое направление обсуждений и исследований, как этика нейронаук, или, проще, нейроэтика [2].

Нейроэтика как возникающая область дискуссий занимается широким кругом вопросов. В частности, медицинские проблемы нейроэтики относятся к таким областям, как неврология, нейрохирургия и психиатрия. Кроме того, нейроэтика имеет и фундаментальное философское значение, поскольку стремительное развитие нейронауки и нейротехнологий затрагивает такие важнейшие понятия, как сознание, поведение и его основы, личность (ее целостность, идентичность и др.), свободу воли.

Необходимость развития новой сферы этических обсуждений стала все отчетливее осознаваться к концу XX века на фоне впечатляющих успехов в исследовании человеческого мозга и нарастания связанных с этим новых моральных проблем. Важнейшим событием для формирования нейроэтики стала конференция в Сан-Франциско в мае 2002 г. под названием «Нейроэтика: создавая карту дисциплины» [3]. На этой конференции был предложен (известным американским журналистом У. Сэфиром) сам термин «нейроэтика» как название области, исследующей моральные проблемы современной нейронауки и технологических вмешательств в деятельность мозга.

В дальнейшем нейроэтика оформляется как самостоятельное поле исследований. В 2006 г. создается Международное общество нейроэтики [4]. Открываются центры нейроэтических исследований при академических учреждениях, появляются специализированные журналы и учебные курсы.

Одна из причин актуальности нейроэтики состоит в том, что широкие возможности нейронауки выходят далеко за пределы традиционно понимаемых благих целей науки. В частности, нейротехнологии могут использоваться в военном деле и в работе спецслужб. В этой связи в 2009 г. Национальный исследовательский совет США опубликовал специальный отчет, посвященный оценке использования нейронауки в военных целях, под названием «Возможности нейронауки для будущих военных приложений» [5].

Нейротехнологии - тема бурных дискуссий. Под нейротехнологиями понимаются современные способы работы с человеческим мозгом (техники воздействия на мозг или взаимодействия с ним). Нейротехнологии представляют собой часть так называемой группы NBIC (конвергентных технологий). Комплекс нейротехнологий включает новые мощные психофармакологические препараты, имплантируемые в мозг чипы, высокие технологии изображений (визуализации) мозга, внечерепную магнитную стимуляцию и др.

К примеру, одна из наиболее активно обсуждаемых тем нейроэтики - семейство технологий нейровизуализации, или нейроимиджинга (компьютерная томография, 
диффузная оптическая томография, магнитно-резонансная томография и другие техники). Эти методы предоставляют возможности глубокого изучения морфологии и физиологии головного мозга, что имеет огромное значение для диагностики психопатологии, а также для технической поддержки нейрохирургических вмешательств.

Методы нейроимиджинга имеют очень широкую сферу применения. К основным этическим проблемам научно-медицинского применения нейроимиджинга можно отнести следующие. Результаты, полученные посредством нейроимиджинга, могут содержать непредвиденные данные о том или ином пациенте (например, это может быть диагноз психиатрического или неврологического расстройства или высокий риск развития патологического состояния).

Соответственно, сообщение о таких находках может повлиять на жизненную ситуацию индивида - от причинения психотравмы до необходимости принятия решений о дальнейшем обследовании, лечении, изменении образа жизни и т.п.

Кроме того, следует иметь в виду, что прогнозы на основе данных нейроимиджинга могут сами по себе причинить вред индивиду, поскольку они могут относиться к патологическим состояниям, для которых в настоящее время нет средств лечения; либо же они могут иметь лишь вероятностный характер без гарантии точности. В этом смысле предсказательные суждения по результатам нейроимиджинга подобны генетическим прогнозам.

Отдельной проблемой является обеспечение конфиденциальности участников исследований в области нейроимиджинга, так как при нейровизуализации имеется возможность идентификации того или иного участника по уникальным характеристикам получаемого изображения (например, можно воссоздать его лицо либо идентифицировать его по индивидуальным особенностям активности мозга). С накоплением массивов данных эта проблема оказывается все более актуальной.

Следует отметить также, что технологии нейровизуализации позволяют выявлять конкретные психические состояния человека, что в некотором смысле является приближением к «чтению мыслей». Широко обсуждается сегодня техническая возможность использования нейроимиджинга в качестве «детектора лжи» нового поколения.

Так, имеются данные исследований, согласно которым можно различить, видит ли мозг знакомую (уже виденную) или незнакомую картину. Если предъявить подозреваемому картину места преступления, то становится возможным установить, бывал ли он на этом месте. При развитии соответствующих технических средств это можно будет применять к уголовным расследованиям.

Аналогичным образом, «чтение мыслей» или распознавание каких-то психических особенностей индивидов может быть использовано для диагностики тех или иных личностных свойств, склонностей человека (например, склонности к противоправному поведению, агрессивности, алкоголизму, наркомании и др.). Уже сейчас высказывают опасения, что это может привести к изменениям в законодательстве, социальной политике, трудоустройстве (к примеру, если будет введено обязательное прохождение нейроимиджинга при приеме на какие-либо должности) и т.п.

Далее, определение эмоциональных состояний человека посредством функционального ядерно-магнитного резонанса (fMRI) может быть использовано для распознавания и выявления тех или иных индивидов с целью предупреждения террористических актов; в настоящее время ведутся разработки дистанционных fMRI сканеров, которые могут быть пригодны в том числе для систем общественной безопасности (их можно, например, устанавливать в местах скопления людей).

Очевидный интерес технология fMRI имеет и для оборонных ведомств.

Вероятно, тревоги общественности пока обгоняют реальные возможности нейроимиджинга. Немалый вклад в «разогрев» таких страхов вносит пресса. Кроме того, необходима действительно высокая надежность получаемых данных, чтобы их можно было использовать как свидетельства в суде или для других целей. Тем не менее, растущий 
технический потенциал нейроимиджинга заставляет уже сегодня обсуждать и анализировать моральные, социальные, культурные, политические следствия развития технологий невровизуализации [6].

С фундаментальной точки зрения, развитие нейроимиджинга влечет спорные эффекты морального характера, так как данная нейротехнология впервые создает беспрецедентную возможность выхода к традиционно закрытой реальности - к сознанию других людей.

Помимо того, что это может породить радикально новые социальные практики в обществе, использование нейроимиджинга может привести к нарушению многих традиционных представлений и норм, в том числе подвергнуть опасности такие базисные ценности, как приватность и автономия личности, создать феномен «открытого сознания», и, в итоге - привести к возможности формирования целого «общества людей с прозрачным мозгом».

Еще одно особо актуальное направление обсуждений в области нейроэтики проблема ментального энхансмента [7].

Это поле обсуждений возникло в связи с тем, что в последние десятилетия в исследованиях биохимии мозга были достигнуты значительные результаты, которые порой характеризуют как «революцию нейромедиаторов». В частности, сегодня выяснено, что определенная группа биохимических соединений - нейромедиаторов (серотонин, дофамин, норэпинефрин и др.) имеет фундаментальное значение для деятельности нервной системы. Их уровень и функционирование прямо выражаются в субъективном самочувствии, самооценке, эмоциях и реакциях индивида и др.

Уже сейчас психофармакология имеет на вооружении мощные средства, которые могут влиять на человеческое сознание (управлять настроением, поведением, вести к личностным изменениям). Одним из ярких примеров нейроэтических проблем является массовое применение за рубежом таких препаратов, как риталин и прозак.

Риталин - психотропный стимулятор, по структуре близкий наркотику кокаину. Он активно используется в настоящее время для лечения синдрома «дефицит внимания и гиперактивность» (ADHD), диагноз которого часто ставят слишком подвижным детям. Действие риталина - повышение внимания, улучшение способности сосредоточиться, легкая эйфория. Его широкое потребление стало государственной проблемой в развитых странах, особенно в США. Риталин имеет серьезные побочные эффекты, но есть заинтересованные группы, которые лоббируют его широкое использование.

Данный препарат фактически стал инструментом медикаментозного решения проблем воспитания «слишком подвижных» детей. Причем многие специалисты подвергают критике сам синдром ADHD как некое социально сконструированное новое «заболевание».

Антидепрессант прозак (повышающий уровень нейромедиатора серотонина) оказывает сложное психотропное воздействие, устраняя депрессию, снижая агрессивность, улучшая самооценку человека, повышая чувство собственной ценности. При этом отмечено, что он вызывает определенные личностные изменения (человек в некотором смысле становится «другим» - происходит некая перемена интересов, установок, ценностей). Препарат имеет немало побочных эффектов. В США чуть ли не каждый десятый (особенно женщины) принимают прозак или его аналоги.

Важно отметить, что прозак применяется не только как лекарство для лечения психопатологии, но даже как средство решения жизненных проблем (таких, как подчиненность, отсутствие решительности и уверенности в себе, карьерные неудачи и т. п.) [8].

Кроме того, сегодня разрабатываются психофармакологические препараты нового поколения. Их можно использовать для создания нужного настроения, усиления памяти, повышения психологического комфорта и т.п. Так, препарат модафинил обеспечивает длительное бодрствование (можно не спать и быть активным долгое время); он уже нашел 
применение в армии США и НАТО. Его назначают военным, несущим дежурство, летчикам, выполняющим ночные полеты и т.п. [9].

Вполне ожидаемо, что скоро общество получит возможность «ментального микроменеджмента» - ежедневного управления настроениями и психологическими состояниями. Новые психофармакологические средства могут использоваться не только для лечения заболеваний, но и для психологического энхансмента, т.е. достижения «сверхнормы» функционирования человеческого мозга. Уже сейчас появился термин «косметическая психофармакология», отражающий новые возможности нейропрепаратов.

Еще одно бурно развивающееся направление нейротехнологии - внечерепная (транскраниальная) магнитная стимуляция мозга. Этот метод начинают применять для лечения хронических болевых синдромов, купирования симптомов болезни Паркинсона; продвигаются также исследования по лечению этими средствами депрессии и других психопатологических состояний. Кстати, отдельной проблемой является безопасность этих новых методов, поскольку их долговременные эффекты пока не проверены в достаточной мере.

Кроме того, методы стимуляции мозга, согласно оценкам экспертов, можно применять для энхансмента: для продления периода бодрствования, для улучшения памяти, процессов обучения и других когнитивных функций.

Применение нейротехнологий с целью ментального энхансмента размывает границы понятий «здоровье» и «болезнь», «норма» и «патология». Возникает множество социальных и культурных неопределенностей. В итоге это может привести к непониманию, где же «подлинный» человек, если его «человеческие» чувства и эмоции (такие, как грусть, тревога, вина, просто плохое настроение) можно «исправлять» лечебными средствами?

Особая проблема для публичного контроля за исследованиями в области нейронаук состоит в том, что по ряду очевидных причин некоторые исследования в сфере новых нейротехнологий могут быть засекречены и закрыты для доступа общественности.

Таким образом, разработки в области нейронауки представляют собой сложное поле совершенно новых проблем, пока плохо исследованных в этическом отношении. Нейроэтика как новое направление исследований должна внести важный вклад в распознавание возникающих рисков, своевременное реагирование на них, а также содействовать созданию регуляторных мер, которые могли бы предвидеть неблагоприятные последствия нейронауки, заблаговременно реагировать на них («принцип предосторожности») и стимулировать наиболее перспективные, социально приемлемые области исследований в сфере нейронаук.

$$
* * *
$$

1. Oxford Handbook of Cultural Neuroscience and Global Mental Health / J. Y. Chiao, Shu-Chen Li, R. Turner, Su Yeon Lee-Tauler, B. Pringle (Eds.). Oxford University Press, 2021.

2. The Routledge Handbook of Neuroethics / L. Syd M. Johnson, K. S. Rommelfanger (Eds.). CRC Press, 2018.

3. Neuroethics: mapping the field. Conference proceedings. San Francisco, California, 2002.

4. https://www.neuroethicssociety.org/ (accessed 07.09.2021)

5. Opportunities in Neuroscience for Future Army Applications. National Research Council, The National Academies Press, Washington D.C., 2009.

6. Racine E., Illes J. Emerging Ethical Challenges in Advanced Neuroimaging Research: Review, Recommendations and Research Agenda. Journal of Empirical Research on Human Research Ethics: An International Journal, 2007, 2, pp. $1-10$

7. Colzato L. S. Responsible Cognitive Enhancement: Neuroethical Considerations. Journal of Cognitive Enhancement, 2018, 2, pp. 331-334.

8. Kramer P. D. Listening to Prozac. A Psychiatrist Explores Antidepressant Drugs and the Remaking of the Serf. Viking Press, 1993.

9. Colzato L. S., Mourits R. Modafinil. / L. S. Colzato (Ed.). Theory-driven approaches to cognitive enhancement. New York: Springer, 2017, pp. 115-126. 